\title{
Attribution of intention as a function of physiognomy*
}

\author{
JULIAN HOCHBERG \\ Columbia Uninersity. lew York. lew York 10027 \\ and \\ RUTH ELLEN GALPER \\ City College of the City Cniversity of Vew York, New York, New York 10031
}

\begin{abstract}
Ss agree in attributing character traits to strangers' photographs. but there has been no explication of what such labels imply. Presumably, trait names either mediate or reflect Ss' expectations of such strangers' likely social behaviors: but that remains undemonstrated. and we may be able to study such physiognomy-tied expectations directly. Sampling problems confront trait studies and intention studies alike, but the present research showed that Ss' expectations of a person's behavioral intentions, as measured by alternative interpretations of short "scenarios, "were reliably influenced by that person's photograph.
\end{abstract}

There is a considerable body of research indicating that, when observers are asked to rate pictures of faces in terms of personality traits, their ratings show a higher consensus than might be expected by chance (cf. Brunswik \& Reiter. 1937: Samuels, 1939: Secord, Dukes, \& Bevan. 1954: Secord. 1958). It seems likely that this agreement reflects more general response patterns of social expectation that have been acquired in the course of social interactions outside of the laboratory. But the importance and usefulness of such agreements are severely limited by the fact that we know nothing about the meaning of traits of this kind, aside from their dictionary definitions and their intercorrelations. It has even been proposed that the sole meaning of a trait consists in its correlations with other traits (Bruner. Shapiro, \& Tagiuri. 1958). Were this all that a trait signified. the fact that a given trait is attributed to some person would only permit us to predict the other traits that would be attributed to him-hardly a significant contribution to our knowledge about social perception.

The consequences of the fact that traits are reliably attributed to faces are completely unknown at present. In the absence of information to this point. the body of literature is difficult to interpret and cannot be applied to the phenomena of interpersonal relationships.

Presumably, the reason that we ask people to assign traits to faces is that we wish to use their responses as surrogates for other actions that they might take or to predict other judgments that they might make. But we cannot simply assume that the trait names that a $\mathrm{S}$ attributes to a face have any implications concerning other responses that he might make to that person. In the case of the perception of the physical properties of physical objects. One cannot assume that all of the

*This research was supported by a grant from XICHHD (1 R01 HD 04213). various responses that would be appropriate to a given property will be consistent with each other. Ss' verbal estimates of an object's distance. for example. often fail to predict their performances on tasks that require them to make other responses to that distance (such as ball throwing, reaching. etc.: cf. Smith \& Smith, 1966). Not only are Ss' judgments unpredictive of other kinds of behavior but also their estimates of one set of object properties are often not predictive of their estimates of other object properties that would be tied to the first set of properties if perceptual structure consistently reflected physical structure. Thus, with a constant stimulus situation. one member of each of the following pairs would be expected to predict the other: perceived size and perceived distance. perceived slant and perceived shape, perceived illumination and perceived reflectance. In fact. such prediction often fails (cf. Hochberg, 1971, pp.406. 505-517). And we have no reason to believe that the situation is any different when we have collected judgments about social properties. such as trait names. In fact. the case is somewhat worse. because we do not know what other kinds of responses trait naming is intended to predict.

Perhaps trait names are labels for categories of behavioral expectation. For example, any person's portrait. either through momentary expression or because of physiognomic endowment. might offer the viewer one of the facial gestures or stances by which "deniable communications" (Goffman. 1967) proceed and by which interchanges are guided and their linguistic and social ambiguities resolved (Hochberg. 1972). It might be because of what the person appears to intend by such gesture that the observer generalizes. inferring that some appropriate trait is characteristic of the person being portrayed. Then the fact that a given person"s face is reliably rated as being high in some trait (or in some cluster of traits) should imply that perceivers will reliably attribute intentions (or probable behaviors) in that person. 
This speculation, which is advanced here because it accords well with recent theories about the perception of physical properties (cf. Hochberg, 1972), makes attributed intention the response that we wish to predict when we obtain trait names. And, even without such speculation, attributed intentions would seem to be of greater interest for the prediction of interpersonal behavior than are mere trait names. There are no data at present, however, to support the supposition that trait names represent categories of behavioral intention, nor that intentions. like traits, are reliably attributed to unknown faces. The experiments reported here were designed to determine whether such attributions of intention can indeed be reliably obtained in response to photographs of unknown persons.

\section{METHOD}

A preliminary experiment was performed using a set of six female faces, selected from a larger set of such photographs, for which Secord et al (1958) had already published factor loadings on trait-attribution data. The faces were selected to provide a range of loadings on two of the factors extracted by Secord and Muthard (1955), i.e., sexuality and social desirability.

Two short dyadic scenarios were composed, each describing a brief interchange between a target person and one other person: a secretary (target) and her boss (SEC scenario); and a social worker (target) and her client (SW scenario). Each interchange ended with an ambiguous statement by the target person. followed by a set of four possible alternatives as to what the women "really meant." In SEC. one alternative (SEC 1) attributed highly sexual intentions to the target; in SW, one alternative (SW 4) attributed the socially undesirable intention of trying to solicit a bribe. Ss, tested in groups. were shown the photographs and asked to indicate which alternative intention was most probable had the speaker been, in turn. each of the six women. Ss thus assigned intentions to each of the six faces for each of the two scenarios. The sequence of presentation of the faces and the scenarios was counterbalanced and randomly distributed among Ss. ${ }^{1}$

The data appeared to show very clearly that Ss attributed the sexual intention almost exclusively to Secord's "highly sexual" face and the socially undesirable intention, similarly, to the "socially undesirable" face. Because Secord's photographs had been taken in the early 1950s, when typical hair styles and cosmetic fashions were quite different from their modern counterparts. they might have elicited trait attributions at that time that would be quite different from those made by present-day Ss. For this reason and because greater control of the rating scales for trait-attribution data was now desirable, this experiment was viewed as a pilot study, and a full-scale experiment was then undertaken, employing more recent photographs and a new set of rating scales.

\section{Procedure}

Seventy-three undergraduate students at Brooklyn College, New York University, and Columbia University were presented with an array of six photographs of female faces chosen from the larger population of a college yearbook. [Three of these faces had been shown in a previous study (Hochberg, Kahan, \& Zelnick ${ }^{2}$ ) to elicit clearly different and identifiable trait-attribution patterns on a set of 12 bipolar rating scales. I The photographs were presented in a 2 by 3 photograph matrix printed on an $8 \times 10$ in. page, each photograph measuring $1 \times 13 / 4$ in. Background, poses, and clothing were similar for all photographs.
Ss were also given booklets containing the two scenarios (SEC and SW) developed for the pilot study. They then assigned one of four intentions to each face for each scenario. The sequence of presentation of faces and scenarios was balanced for possible order effects. The instructions and scenarios were as follows:

Instructions. "This is a test of how well people's character can be judged from their pictures. Six photographs appear on the next page. On each following page is part of a conversation, spoken by one of the women. A number of alternative meanings are given for each conversation. Please indicate which alternative best describes what the woman really meant."

$S E C$. "The woman in the photograph is a secretary. She has just been assigned for the first time to the vice-president of the company, who is a young. dynamic. fast-rising married man. He has just thanked her for taking dictation. The woman, standing at the door, asks: 'Is there any thing else you would like?'

"What she really meant by this question. as revealed by subsequent conversation and behavior, was: (1) that she is available for, and interested in, a more personal and intimate relationship; (2) she's making a personal advance, but she doesn't mean to follow through-it's just a way of getting attention: (3) that she is skilled in all aspects of secretarial service-arranging schedules, devising filing systems, etc.-not merely a capable stenographer; (4) she's simply being polite and courteous.

"You might interpret the above conversation differently if different women were involved. Please look at the photographs. and decide which choice (given above) best describes what each woman probably meant."

$S W$ ' "The woman in the photograph is a social worker, who was sent to interview a woman on welfare. This woman was suspected of holding a job while receiving welfare payments, and the social worker has discovered that this is really true. In fact. the woman has even acquired a modest set of investments. After outlining the penalties for such fraud. the social worker says to the client (who is in tears): 'It doesn't have to be as bad as all that. You seem to be an intelligent woman, and I like you. Let's talk about it some more.'

"What she really meant by this, as revealed by subsequent conversation. was: (1) that the woman would get off with a reprimand. if she paid back the money that she shouldn't have received; (2) that there might be some way out of the mess: (3) she is just being kind and reassuring. and is trying to stop the other woman from crying: (4) that she would cover up, if given a sufficient bribe.

"You might interpret the above conversation differently ..." In a second part of the experiment, two groups of 15 judges were asked to rate each of the four intention alternatives for each scenario on the same set of 12 bipolar trait scales on which ratings had previously' been obtained for the six faces (Hochberg. Kahan. \& Zelnick ${ }^{2}$ ). Judges saw the same scenarios and intention alternatives as did $S s$ in the first part of the experiment but were not shown any faces. Instead, they were instructed to rate each of the alternative intentions on the set of trait scales. The scales were bipolar 7-point rating scales, labeled as follows: cheerful-gloomy. outgoing-reserved. strict morals-loose morals. insincere-sincere. emotional-unemotional. unsophisticated-sophisticated, conscientious-unconscientious. kind-unkind, demanding-undemanding. energetic-unenergetic. likable-unlikable. aggressive-unaggressive.

\section{RESULTS}

The intention-attribution procedure was administered to two different sets of Ss at two different times, approximately 1 year apart. Correlation coefficients were calculated for each face by comparing the numbers of Ss from each sample who chose each of the four alternatives. This served two functions: (1) to determine 
whether the two groups of Ss had chosen similar patterns of alternatives for any given face, thus providing a measure of the reliability of the responses to faces, and (2) to indicate whether the two groups could be pooled for subsequent analysis. The alternative intentions clearly differed in the frequencies with which they were chosen, regardless of the face being judged (see Table 1B). In order to determine how much of the intersubject agreement was attributable to the effect of the face rather than to the respective response biases for each of the intentions, the frequency with which Ss attributed any intention to a face was divided by the total frequency with which all Ss had attributed that intention to all faces. The correlations for each scenario appear in Table 1A. The means of their $z$ ' coefficient transformations and tests of the significance of the mean $z^{\prime}$ values for each scenario also appear in Table $1 \mathrm{~A}$. The data for the two groups of Ss were pooled, and the frequencies with which the alternative intentions were attributed to each face appear in Table 1B.

The degree to which the two sets of judges, who had been asked to rate the intentions on the trait scales, agreed about those intentions was measured by correlating the mean ratings that each set gave to each intention on the 12 trait scales (i.e., correlating two sets of 12 mean ratings for each intention). These reliability coefficients are given in Table $2 \mathrm{~A}$. The profiles of mean ratings that each of the six faces had received on the same trait scales (obtained from the data of Hochberg, Kahan, \& Zelnick) were correlated with the profiles of mean trait ratings for each intention. This yielded a measure of the agreement between each face and each intention, in terms of trait ratings. These measures were correiated with the frequencies with which each intention had been assigned to each face (i.e., with the data of Table 1B). The correlations thus obtained are

\section{Table 1}

A. Intergroup Reliabilities of Intention Attributions (Corrected for Response Bias of Each Intention)

Face

\begin{tabular}{ccccccc} 
& 1 & 2 & 3 & 4 & 5 & 6 \\
\hline SEC* & .431 & .998 & .948 & .806 & .942 & .628 \\
SW: & .464 & .854 & .962 & .868 & .972 & .775 \\
\hline
\end{tabular}

B. Pooled Frequencies of Intention Attributions Intention

\begin{tabular}{|c|c|c|c|c|c|c|c|c|}
\hline \multirow[b]{2}{*}{ Face } & \multicolumn{4}{|c|}{ SEC } & \multicolumn{4}{|c|}{ SW } \\
\hline & 1 & 2 & 3 & 4 & 1 & 2 & 3 & 4 \\
\hline 1 & 14 & 23 & 20 & 26 & 24 & 29 & 33 & 7 \\
\hline 2 & 4 & 19 & 19 & 41 & 14 & 37 & 39 & 2 \\
\hline 3 & 52 & 16 & 5 & 10 & 12 & 19 & 16 & 36 \\
\hline 4 & 2 & 6 & 34 & 41 & 15 & 27 & 39 & 2 \\
\hline 5 & 9 & 13 & 41 & 20 & 40 & 20 & 11 & 12 \\
\hline 6 & 6 & 13 & 19 & 45 & 10 & 26 & 40 & 7 \\
\hline
\end{tabular}

*Mean $z^{\prime}=1.56 . t=3.86 . p<.01$

thean $z^{\prime}=$ 1.37. $t=$ 2.44. $p<.05$
Table 2

A. Reliatilities of Trait Ratings of Intentions

Intention

\begin{tabular}{|c|c|c|c|c|c|c|c|}
\hline \multicolumn{4}{|c|}{ SEC } & \multicolumn{4}{|c|}{ SW } \\
\hline 1 & 2 & 3 & 4 & 1 & 2 & 3 & 4 \\
\hline .97 & .35 & $\begin{array}{l}65 \\
\text { ean } \\
\end{array}$ & $\begin{array}{l}.84 \\
=.9 \\
\end{array}$ & $\begin{array}{r}.39 \\
4.95 \\
\end{array}$ & $\begin{array}{l}61 \\
<\end{array}$ & .81 & .83 \\
\hline
\end{tabular}

B. Correlations Between Similarity Measures of Faces and Intentions on Trait Rating Scales and Frequency of Intention Attribution to Each Face (from Table 1B) Face

\begin{tabular}{lcccccc} 
& 1 & 2 & 3 & 4 & 5 & 6 \\
\hline SEC $^{*}$ & .403 & .633 & .508 & .959 & .400 & .742 \\
SW & .589 & .572 & .400 & .504 & .650 & .001 \\
\hline
\end{tabular}

*Mean $z^{\prime}=.84, t=3.67, p<.01$

'Mean $z^{\prime}=.51 . t=3.69, p<.01$

given in Table 2B, with means and $t$ values (via $z^{\prime}$ transformations).

\section{DISCUSSION}

The significant mean $\mathrm{z}^{\prime}$ coefficients in Table $1 \mathrm{~A}$ indicate that Ss agree in their attribution of intentions to faces, even after a correction has been made for differential preferences given the various intentions themselves. The two principal questions, thus, appear to be answered: Physiognomy does affect the attribution of behavioral intentions, and perceivers can reliably attribute intentions on the basis of still photographs of faces. These findings raise many questions that cannot be answered by the present data, perhaps the most interesting of which concern the following: the relationship between attributed traits and attributed intentions: the explanation of why such attributions occur; and their consequence for social interactions (both dyadic and one/many, as in entertainment and politics).

With respect to the relationship between traits and intentions, the face that was expected on the basis of trait data to elicit the attribution of intention SEC 1 (sexual) and intention SW 4 (socially undesirable) did so very strongly $\left(\chi^{2}=122.45 . \mathrm{df}=5, \mathrm{p}<.001\right.$ and $\chi^{2}=74.6, \mathrm{df}=5, \mathrm{p}<.001$, respectively; see Table $1 \mathrm{~B}$ ). Moreover. the measures of similarity between the profiles of mean trait ratings that were attributed to the faces and to the intentions did correlate somewhat with the actual frequencies with which intentions were assigned to faces. at least in the SEC scenario (see Table 2B), showing that faces, intentions. and traits do appear to share some variance. The low correlation may be attributable to the high overlap of trait loadings for the different intentions. A larger sample of traits. intentions, and faces would permit multivariate analyses of the respective spaces that these define and would permit the definition of traits in more behaviorally meaningful terms than does a knowledge of trait 
interrelationships alone. Such analysis might also indicate whether traits or intentions are more closely and directly attributed to faces and, therefore, provide a more adequate basis than does the present sample of variates for deciding whether the traits that are attributed to faces are mediated by perceived intentions, vice versa, or neither. With respect to the consequences of attributed intentions for social interaction, the discovery and codification of such intentions would not only contribute to an understanding of the physiognomically based predispositions that affect our expectations of other persons but also would provide information about our expectations about the interaction process.

\section{REFERENCES}

Bruner. J.. Shapiro. D.. \& Tagiuri. R. The meaning of traits in isolation and combination. In R. Tagiuri and L. Petrullo (Eds.), Person perception and interpersonal behatior. Stanford. Calif: Stanford University Press, 1958.

Brunswick. E. \& Reiter, L. Eindrucks Charaktere Schematisierter Gesichter. Zeitschrift fur Psychologie, 1937, 142, 67-134.

Goffman, E. Interaction ritual. Garden City: Anchor, 1967.

Hochberg, J. Perception: II. Space and movement. In J. W. Kling and L. A. Riggs (Eds.), Woodworth and Schlosberg's experimental psychology. New York: Holt. Rinehart, \& Winston. 1971.
Hochberg. J. The representation of things and people. In $\mathrm{M}$. Mandelbaum (Ed.). Art, perception, and reality: Baltimore. Md: Johns Hopkins University Press, 1972.

Samuels. F. Judgment of faces. Character \& Personality. 1939. 8. 18-27.

Secord, P. F. Facial features and inference processes in inter-personal perception. In R. Tagiuri and L. Petrullo (Eds.). Person perception and interpersonal behavior. Stanford, Calif: Stanford University Press, 1958.

Secord, P. F., Dukes. W. F., \& Bevan, W. Personalities in faces: I. An experiment in social perceiving. Genetic Psychology Monograph. 1954. 49. 231-279.

Secord, P. F.. \& Muthard. J. E. Individual differences in the perception of women's faces. Journal of Abnormal \& Social Psychology, 1955, 50. 238-242.

Smith, O. W., \& Smith, P. C. Developmental studies of spatial judgments by children and adults. Perceptual \& Motor Skills, $1966,22,3-73$.

\section{NOTES}

1. In an earlier test of the procedure. Ss assigned intentions to only one face for each scenario, then afterward. to all six faces. Analysis of the data revealed that face to intention assignments were not significantly affected by this difference in procedure. Therefore, subsequent $S s$ each assigned intentions to each face for each scenario.

2. Hochberg, J., Kahan. B., \& Zelnick, J. Similarities and confusions among photographs of female faces, in preparation.

(Received for publication April 23, 1973; accepted May 2. 1973.) 